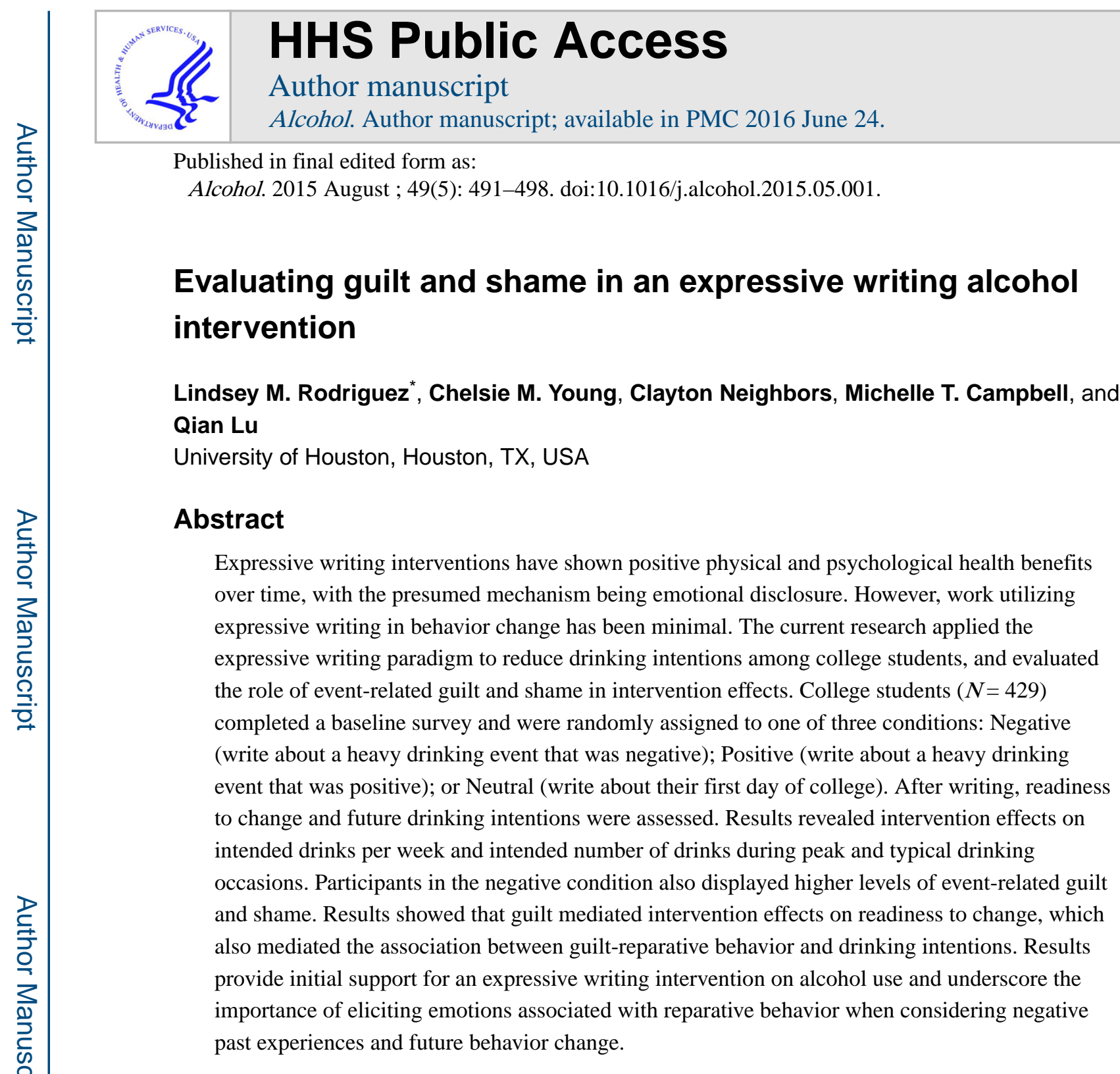

\title{
Keywords
}

Drinking; Reparation; Emotion; Expressive writing; Readiness to change; Intentions

Guilt and shame are emotions that accompany cognitions related to regretted experiences and consideration of behavior change. Among young adults, both positive and negative experiences are often paired with episodes of heavy drinking, which may elicit feelings of shame and guilt, thereby contributing to consideration of behavior change. The present paper examines the effects of writing about heavy drinking events on shame and guilt, readiness to change, and future drinking intentions.

*Corresponding author. Department of Psychology, University of Houston, 126 Heyne Bldg., Houston, TX 77204-5022, USA. Tel.: +1 713743 1546; fax: +1 713743 8588. LRodriguez23@uh.edu (L.M. Rodriguez). 


\section{Alcohol use in college}

Alcohol use is prevalent in college students, with 63\% reporting drinking alcohol and $40 \%$ reporting being drunk in the previous month (Johnston, O’Malley, Bachman, Schulenberg, \& Miech, 2014). Moreover, alcohol use is associated with multiple deleterious consequences such as vomiting, hangovers, unwanted sexual encounters, DUIs, and reduced academic performance (Hingson, 2010; Hingson, Heeren, Winter, \& Wechsler, 2005; White \& Hingson, 2013). Despite much effort to reduce high-risk drinking among college drinkers, prevalence rates of negative alcohol-related consequences have not declined, and serious consequences among older college students (age 21-24) have actually increased (Hingson \& Zha, 2009). Thus, there is a need for brief, inexpensive interventions that can be easily and broadly applied to this population. An adaptation of the expressive writing paradigm, which has been successfully used in other health behavior interventions, is a promising, novel intervention approach for college student drinking.

\section{Expressive writing interventions}

Expressive writing is a brief intervention that has been linked to a multitude of physical health and psychological well-being benefits such as improved immune response (Pennebaker, Kiecolt-Glaser, \& Glaser, 1988), fewer medical center visits (Pennebaker, Colder, \& Sharp, 1990; Stanton \& Danoff-Burg, 2002), reduced physical symptoms(Greenberg, Wortman, \& Stone, 1996; Lu \& Stanton, 2010), decreased pain among chronic pelvic pain sufferers (Norman, Lumley, Dooley, \& Diamond, 2004), greater well-being (Barclay \& Skarlicki, 2009), and higher relationship satisfaction (Baddeley \& Pennebaker, 2011). In the traditional expressive writing paradigm, participants are instructed to reflect on a stressful experience and to write about their thoughts and feelings regarding that experience. Health benefits have been shown in studies in which participants are asked to write for 15-20 min in each session for three or four sessions (Pennebaker, 1997). Expressive writing has been shown to confer positive health effects lasting months after the intervention in both college students and patients (Lu \& Stanton, 2010; Stanton \& DanoffBurg, 2002). It has been postulated that these health benefits occur through emotional disclosure and cognitive processing of traumatic events (Frattaroli, 2006). As such, expressive writing is tied to emotion regulation (Smyth \& Arigo, 2009) and cognitive processes (Smyth \& Greenberg, 2000). Expressing emotions through writing can lower levels of stress and negative effect, thereby serving as a coping mechanism. Additionally, expressive writing paradigms encourage participants to reconstruct their emotional experiences and reorganize their memories of these events into a cohesive narrative, which may also assist in their efforts to better understand and cope with the event (Smyth \& Helm, 2003).

Although expressive writing has been repeatedly linked to improved physical health and psychological functioning, the effect of expressive writing on behavior change is promising yet unclear. The majority of expressive writing studies that focus on writing about stressful events either did not examine health behavior change or did not find behavior change (Ames et al., 2005, 2007; Pennebaker et al., 1988). However, some studies have shown encouraging effects of expressive writing sessions on behavior change. One study found expressive 
writing to be effective in promoting healthy sleep patterns (Harvey \& Farrell, 2003), and another study reported decreased alcohol consumption (Spera, Buhrfeind, \& Pennebaker, 1994). These studies provide potential for the use of modified expressive writing paradigms as brief interventions to reduce problem drinking. Furthermore, a recent study evaluated the effect of writing about a heavy drinking occasion on subsequent drinking intentions. This single session of writing about a negative alcohol-related experience reduced drinking intentions (Young, Rodriguez, \& Neighbors, 2013). The study suggests that writing about health behavior may have a strong impact on behavior change, and incorporating health behavior into the expressive writing paradigm might be a powerful tool to change behavior.

The primary goal of the current study is to evaluate the effectiveness of two types of writing instruction (i.e., negative vs. positive heavy drinking event) in comparison with writing about a neutral event. Based on the literature of expressive writing and results from Young et al. (2013), we hypothesize that participants writing about a negative drinking event will show reduced drinking intentions relative to students in the neutral control group. However, the previous study did not explore the mechanism by which writing about a negative drinking event may lead to decreased drinking intentions. This research examines whether emotions related to the drinking event (i.e., shame and guilt) might mediate intervention effects.

\section{(Event-related) Shame and Guilt}

Shame and guilt are conceptualized as negative, morally-based, self-conscious emotions (Tangney, 1991; Tangney \& Dearing, 2002; Tangney, Stuewig, \& Mashek, 2007). Both are experienced with reference to evaluation of the self and are typically experienced in social situations. Although these concepts share considerable overlap, they are conceptually distinct. The prevailing delineation of shame and guilt by Lewis (1971) is such that when an individual experiences shame, he/she feels badly about the self (" $I$ did that horrible thing"), whereas when an individual experiences guilt, he or she feels badly about engaging in a specific behavior ("I did that horrible thing"). Guilt is typically concerned with how one's actions affect others, whereas shame is generally concerned with how others will perceive oneself based on one's actions. Thus, shame and guilt differ both in the evaluation of the self and the behavior following the experience of the particular emotion. Research has shown that shame is considered to be a more painful experience than guilt, is associated with feeling small, and that those who feel ashamed often want to run away or hide (Tangney \& Dearing, 2002). Guilt is thought to be less painful than shame and associated with feeling tense or regretful (Tangney \& Dearing, 2002). Those experiencing guilt seek repentance and reparation for their actions (Tangney \& Dearing, 2002). Guilt is thought to focus on making amends for past indiscretions and, as such, has been associated with enacting positive, responsible behaviors. Conversely, shame is thought to focus on negative evaluations of the self and has been associated with later engagement in risky and harmful behaviors (Tangney \& Dearing, 2002).

Guilt has been considered a more adaptive emotion whereby positive strides are taken to improve the self and to make amends for past transgressions. Conversely, shame can lead to a depressive attribution style that devalues the self and can result in harmful and severe 
health outcomes such as anxiety, depression, drug use, and suicide (Hoblitzelle, 1987;

Lewis, 1987; Tangney \& Dearing, 2002). Relevant to the current research, Dearing and colleagues found that shame-proneness was positively associated with problem alcohol use, whereas guilt-proneness was negatively related to problem alcohol use (Dearing, Stuewig, \& Tangney, 2005). Thus, the current study proposes that experiencing shame and guilt will be differentially effective in reducing drinking intentions. Specifically, shame is expected to be less effective, whereas guilt is expected to be more effective in reducing drinking intentions. A natural bridge between expressions of shame and guilt and intentions to change is motivation to change. In other words, readiness to change might be a proximal consequence of shame and guilt and an antecedent of behavioral intentions.

\section{Readiness to change}

Readiness to change (RTC) has been proposed as a component of behavior change in the field of addictions (Borsari, Murphy, \& Carey, 2009; DiClemente, Schlundt, \& Gemmell, 2004; Prochaska, DiClemente, \& Norcross, 1992). This construct has provided a useful heuristic in helping us understand when and why people initiate behavior change (Miller \& Rollnick, 2002). It has been more often considered as a predictor of behavior change, though evidence suggests that the temporal direction is complex among young adults (Collins, Logan, \& Neighbors, 2010). Less work has focused on predictors of readiness to change, but recollection of negative alcohol-related experiences and accompanying feelings of guilt would seem to be prime candidates. Thus, the current study will test event-related guilt and shame as precursors to readiness to change one's drinking, which in turn is expected to predict future drinking intentions.

\section{Current research}

The current research was designed to apply the expressive writing paradigm to alcohol use intentions in college student drinkers and to evaluate whether event-related guilt and shame would mediate the intervention effect. We hypothesized that writing about a negative heavy drinking occasion would be associated with increased readiness to change and reduced intentions to drink in the future when compared to control. Based on previous research (e.g., Young et al., 2013), we expected that the positive condition would either increase drinking intentions and decrease readiness to change or have no effect on these outcomes compared to control. Because positive narratives focused on heavy drinking occasions in which participants had a good time, we did not expect significant associations between eventrelated shame and guilt in the positive drinking narrative condition. However, we expected that writing about a negative heavy drinking occasion would be associated with increased shame and guilt. Based on the shame and guilt literature, we expected that event-related guilt would predict increases in readiness to change and decreases in drinking intentions, whereas we expected that event-related shame would predict either no changes in readiness to change and drinking intentions or poorer outcomes (i.e., reduced readiness to change, higher drinking intentions). Thus, we hypothesized that the intervention effect would be mediated by event-related guilt, but not shame. Given the preliminary nature of this research, we did not have specific hypotheses distinguishing between the two dimensions of guilt or the two dimensions of shame measured in the current study. 


\section{Method}

\section{Participants and procedure}

Participants were required to report having consumed at least one alcoholic drink per month to participate, which participants confirmed before being taken to the informed consent page. Participants included 495 undergraduate students. However, when asked how often they typically drink, 66 participants $(9.9 \%)$ indicated "never" or "less than once per month". These participants were dropped from the analysis. Thus, the final sample consisted of 429 participants ( $78.4 \%$ female) who were, on average, 22.4 years old ( $\mathrm{SD}=4.92$ years). The sample was racially diverse, with $42.9 \%$ Caucasian, $21.9 \%$ Asian, $16.2 \%$ African American, 4.6\% Multi-Ethnic, $1.2 \%$ Native American, .8\% Native Hawaiian, and $12.4 \%$ Other.

Participants were recruited from the psychology department to participate in the online study and received extra course credit for their participation. Participants were first asked about their current alcohol use. Then, they were randomly assigned to write about either (a) a positive heavy drinking occasion, (b) a negative heavy drinking occasion, or (c) their first day of college (control condition). The prompt for the negative condition was as follows: "Please tell us about an occasion when you drank alcohol heavily and had a bad time or experienced things you did not want to experience as a result of your drinking. We would like you to be as descriptive as possible. For example, what specific things made this event so negative for you?" The prompt for the positive condition was as follows: "Please tell us about an occasion when you drank alcohol heavily and had a good time or experienced things you wanted to experience as a result of your drinking. We would like you to be as descriptive as possible. For example, what specific things made this event so positive for you?" Finally, the neutral prompt asked participants, "Please tell us about your first day of college. We would like you to be as descriptive as possible. For example, what specific things do you recall?" Prompts for all conditions ended with, "Please write a complete paragraph detailing your experience." Immediately following the expressive writing session, participants responded to questions regarding guilt and shame surrounding the target event, readiness to change their drinking behaviors, and their intended future alcohol use.

\section{Measures}

Baseline drinking-Baseline drinking was operationalized as the number of drinks per week, drinking frequency, and number of drinks consumed during both a typical drinking occasion and a peak drinking occasion in the past month. The number of drinks per week was assessed with the Daily Drinking Questionnaire (DDQ; Collins, Parks, \& Marlatt, 1985). The current study asked, "Consider a typical week during the last month. How much alcohol, on average (measured in number of drinks), do you drink each day of a typical week?" The weekly drinking score was created by taking the sum of the given standard number of drinks for each day of the week. Drinking frequency and number of drinks during a typical and peak drinking occasion were measured with the Quantity/Frequency/Peak Alcohol Use Index (QF; Dimeff, Baer, Kivlahan, \& Marlatt, 1999). The QF is a scale designed to identify typical drinking patterns over the previous month. This questionnaire includes an item addressing typical number of drinking days per week in the previous month (i.e., drinking frequency), an item addressing typical weekend drinking in the previous 
month (i.e., typical drinking), and an item addressing the occasion where respondents drank the most during the previous month (i.e., peak drinking). Drinking frequency was assessed on a 12-point scale $(1=$ never, $2=$ less than once per month; $3=$ once per month; $4=$ two times per month; $5=$ three times per month; $6=$ once a week, $7=$ twice a week, $8=$ three times a week, 9 = four times a week, 10 = five times a week, $11=$ six times a week, $12=$ every day). Typical and peak drinking response options range from 0 to $25+$ standard drinks (e.g., 12 oz. beer, 5 oz. wine).

Event-related guilt and shame-Event-related guilt and shame were assessed using items based on the content and structure of the Test of Self-Conscious Affect (TOSCA-3 revised; Tangney, Dearing, Wagner, \& Gramzow, 2000), modified to ask participants to think back to the event and imagine feelings and thoughts as they experienced them at the time of the event. Participants indicated their agreement with 40 items from 1 (Strongly disagree) to 5 (Strongly agree). Four subscales were constructed, each consisting of 10 items. Consistent with the revised TOSCA, these included: (a) guilt-affect and cognition; (b) guilt-reparative behavior; (c) shame-negative self-appraisal; and (d) shame-behavioral avoidance. All items are presented in the Appendix.

The guilt-affect and cognition subscale assessed general disappointment or dissatisfaction with the behavior. Example items included "You felt bad that you let people down", "You felt guilty", and "You wondered if you could have done better" $(\alpha=.96)$. The guiltreparative behavior subscale represents a desire to correct any mistakes from the event (e.g., apologizing) or resolving to be more careful in the future. Example items included, "You decided to compensate for your shortcomings by trying harder in the future", "You decided to make it up to people as soon as you could", and "You took responsibility for your actions and their consequences" $(a=.96)$. The shame-negative self-appraisal subscale assessed shame and embarrassment. Example items included "You felt like a failure", "You felt ashamed", and "You felt like people were watching you and laughing at you" $(\alpha=.96)$. Finally, the shame-behavioral avoidance subscale measured the extent to which individuals wanted to escape from the experience due to its negative aspects. Example items included "You felt like you wanted to hide", "You tried to forget that the experience ever happened", and "You were so afraid of some people's reactions that you made efforts to avoid telling them about the experience" $(a=.95)$.

Readiness to change drinking behavior-Readiness to change was assessed with the Readiness to Change Questionnaire (RTCQ; Heather, Gold, \& Rollnick, 1991; Rollnick, Heather, Gold, \& Hall, 1992). This 12-item questionnaire asked participants to indicate their agreement with statements about thoughts regarding their drinking on a scale from 1 (Strongly disagree) to 5 (Strongly agree). Example items included, "Sometimes I think I should cut down on my drinking", "I am at the stage where I should think about drinking less alcohol", and "It's a waste of time thinking about my drinking" (reverse-scored) ( $\alpha=$. 70). The RTCQ is composed of three subscales (i.e., pre-contemplation, contemplation, and action), which are weighted and combined to create an overall readiness to change score.

Drinking intentions-Finally, participants were asked to report their intentions for drinking over the next month. Drinking quantity and frequency were assessed by modifying 
the DDQ and QF. Response options were identical to the baseline drinking items, but participants were asked to indicate their intended drinking behaviors. Participants were asked how much alcohol they intended to drink on each day of a typical week over the next month, which was summed to create the intended drinks per week score. Participants were asked how often they intended to drink alcohol in the upcoming month (i.e., intended drinking frequency), how many drinks they intended to consume on a typical drinking occasion (i.e., intended typical drinking) and how many drinks they intended to drink on a peak drinking occasion (i.e., intended peak drinking).

\section{Results}

\section{Descriptive statistics}

Table 1 presents descriptive statistics for all study variables by condition. Table 2 presents correlations among all study variables. Generally, experiencing higher levels of shame and guilt was positively associated with readiness to change and negatively associated with drinking intentions. Collapsing across condition, all measures of shame and guilt were positively associated with readiness to change. Both subscales of shame were negatively associated with three of the four drinking intentions variables. The affect/cognition subscale of guilt was significantly negatively associated with intended drinking frequency and marginally with intended typical and peak drinks. Finally, the reparative behavior subscale of guilt was negatively associated with intended drinking frequency and intended peak drinks, and was marginally negatively associated with intended drinks per week.

\section{Intervention effects}

Before evaluating mediation models, we first examined the effects of writing about a positive and negative drinking occasion on future drinking intentions and readiness to change. There were no differences in any of the baseline drinking variables based on condition (all $p$-values $>.50$ ). Two contrasts were dummy-coded to represent the positive and negative conditions relative to the control condition. Main effects of both contrasts and gender were entered into a multiple regression equation predicting each drinking outcome. Results with parameter estimates and tests of significance for all outcomes and readiness to change are presented in Table 3. Overall, compared to control, writing about a positive heavy drinking event was not associated with readiness to change or any drinking intention outcome (all $p$-values > .10). However, relative to control participants, individuals assigned to write about a negative heavy drinking event reported intending to drink fewer drinks per week, $t(417)=-2.36, p=.019$, fewer drinks on a future peak drinking event, $t(417)=-2.05$, $p=.041$, and fewer drinks on a typical drinking occasion, $t(416)=-2.00, p=.047$. There were marginal intervention effects in the expected direction for intended drinking frequency, $t(414)=-1.73, p=.085$, and readiness to change, $t(419)=1.66, p=.098$.

\section{Mediational model}

Analysis plan-The mediational model of interest was run using the AMOS 20.0 program. Parameters were estimated using full information maximum likelihood estimation (Schafer \& Graham, 2002). This model included both dummy-coded contrasts (i.e., negative vs. control and positive vs. control) predicting all four indicators of guilt and shame, which 
then predicted readiness to change, and then predicted drinking intentions. Intended drinks per week, drinking frequency, and number of drinks during a typical and peak occasion were modeled as indicators of a latent drinking intentions variable. Baseline drinking (also created as a latent variable) and gender were entered as covariates in the model. Overall, the model fit the data well, $\chi^{2}(79)=145.00, p<.001, \mathrm{CMIN} / \mathrm{DF}=1.835, \mathrm{RMSEA}=.044, \mathrm{CFI}=.980$, $\mathrm{TLI}=.966, \mathrm{NFI}=.959, \mathrm{IFI}=.981$. Results from the model with standardized estimates may be seen in Fig. 1.

Compared with control, writing about a negative heavy drinking event was associated with higher levels of both subscales of guilt and both subscales of shame (all $p$-values $<.001$ ). Additionally, writing about a positive heavy drinking event was associated with lower levels of shame and guilt when compared to the neutral condition. When evaluating the effects of guilt and shame on readiness to change, only one subscale of guilt and shame was associated with readiness to change, guilt-reparative behavior $(\beta=.18, p=.005)$. Finally, readiness to change was negatively associated with drinking intentions $(\beta=-.21, p<.001)$.

Mediation analyses-To evaluate shame and guilt as mediators of intervention effects on readiness to change, we used the $a b$ products method suggested by MacKinnon, Lockwood, Hoffman, West, and Sheets (2002). Significance tests were performed by computing asymmetric $95 \%$ confidence intervals with the PRODCLIN program (MacKinnon, Fritz, Williams, \& Lockwood, 2007). Significance is indicated by confidence intervals that exclude zero. Results indicated that only the indirect effect of writing about a negative drinking event on readiness to change through guilt-reparative behavior was significant $(95 \%$ CI $[.027, .200])$. Direct effects of the intervention on readiness to change were not significant.

PRODCLIN was also used in testing readiness to change as a mediator of the association between guilt-reparative behavior and drinking intentions. Gender and baseline drinking were again included as covariates. We examined the indirect path from the guilt-reparative behavior subscale to intended drinking behavior through readiness to change, controlling for gender and baseline drinking. As expected, the association between reparative behavior and reduced drinking intentions was mediated by readiness to change (95\% CI [-.197, -.030]). Direct effects of guilt and shame on drinking intentions were not significant.

\section{Discussion}

A central aim of the present research was to examine how writing about a negative or positive drinking event would be associated with differences in event-related shame and guilt. We were also interested in how event-related shame and guilt might be associated with subsequent readiness to change and drinking intentions. Results indicated significant intervention effects (i.e., negative expressive writing vs. control) on three of the four drinking intentions outcomes (i.e., drinks per week, number of drinks during a future peak drinking occasion, and number of drinks during future typical drinking occasions), with marginal effects for intended drinking frequency and readiness to change. Additionally, as expected, the negative expressive writing condition reported significantly higher levels of both event-related shame and guilt. Zero-order associations demonstrated that all subscales 
of shame and guilt were positively associated with readiness to change. We found partial support for the hypothesis that the effect of writing about a negative heavy drinking event would be mediated by guilt. As anticipated, neither shame subscale predicted readiness to change. However, only the reparative behavior guilt subscale was associated with readiness to change. Mediational analyses showed that only the reparative behavior subscale of guilt mediated the association between the intervention and readiness to change scores. Finally, results from the second set of mediational analyses revealed that the association between guilt (reparative behavior) and drinking intentions was indeed mediated by readiness to change. Thus, it appears that perceived guilt, specifically, the desire to correct one's past missteps, is a key reason that writing about a negative heavy drinking event reduces future intentions to drink.

Much of the expressive writing literature focuses on mechanisms through which beneficial effects occur. In this paradigm, it seems that the act of self-reflection and consideration of one's choices, in light of not repeating past mistakes, enacts motivation for change.

Adopting a notion from quantum physics, the Heisenberg principle (e.g., Landau \& Lifshitz, 1977) states that the mere act of observing alters the very reality being observed. In this case, re-experiencing the memory of the heavy drinking event elicits a reorganization of the memory itself. Asking individuals to focus on the negative aspects may have actually altered their memories of the event or the extent to which the event was perceived as positive vs. negative. Importantly, perhaps the critical mechanism of intended change in this context is the insight that occurs because of reliving decisions that led to unwanted consequences. Indeed, a preliminary look into the text of the narratives showed that individuals reported a variety of negative consequences such as sexual assault, conflicts with friends and family members, confrontations with law enforcement, and major vehicle accidents.

The present results expand upon a prior examination of shame and guilt in the context of alcohol use (Dearing et al., 2005). Previous research examined individual differences in the tendency to experience shame and guilt (i.e., proneness) and found expected associations with problem alcohol use. Conversely, the present study focused on feelings of shame and guilt related to a specific experience. Furthermore, the present research used an experimental design to examine shame and guilt as outcomes and mediators of motivations and intentions for changing drinking, thus providing an initial glimpse into the causal processes involved in alcohol-related shame and guilt and changes in drinking intentions.

Among the points that are worthy of discussion, it is interesting to note that shame and guilt related to a specific drinking event appear to have limited associations with readiness to change and drinking intentions (see Fig. 1). Shame in this context does not appear to have positive or negative effects on drinking outcomes. In contrast, the reparative behavior subscale of guilt was positively associated with readiness to change and negatively associated with two of the measures of drinking intentions. Moreover, experiencing affective and cognitive guilt surrounding one's actions or feeling sorry was not sufficient to affect readiness or intentions. Rather, readiness and intentions were only influenced when narratives were followed by a desire to compensate, take responsibility, or make reparative actions in response to guilt. While more research is needed, it is possible that the individual 
difference of guilt- and shame-proneness might function differently than event-specific guilt and shame.

The present research has potentially important practical applications in that it provides initial support for expressive writing as an experimental strategy for affecting guilt and shame. It also supports previous considerations of the utility of considering guilt and shame in therapeutic contexts (Tangney \& Dearing, 2002). There are specific applications that might follow from the present results. First, while expressive writing appears to have some promise as a brief intervention technique, it will likely require multiple sessions and/or consideration of multiple heavy drinking episodes. A single session discussing a single event does not appear to constitute sufficient dosage to have a significant impact. Second, while these results did not show increased drinking intentions as a function of shame, there were also no positive effects of shame. Thus, there is presently no support for encouraging individuals to express shame in their expressive writing narratives.

Third, one of the considerations suggested by Young et al. (2013) is that expressive writing may be a vehicle for encouraging individuals to engage in change thought. The verbal analogue of change thought (i.e., change talk) has been found to be a key ingredient in the effectiveness of motivational interviewing (Miller \& Rollnick, 2012). The present research suggests more specifically how instructions might be crafted. Thus, instructions for expressive writing interventions might be best tailored by asking participants to write about events in which they experienced guilt and a desire to make reparations. Alternatively, participants could be asked to write ideas about how they could make corrections to prevent experiencing similar negative alcohol-related consequences in the future.

\section{Limitations and future directions}

The implications of this research should not be considered without its limitations. First and foremost, the current study was cross-sectional and could only assess drinking intentions. A logical next step is to collect follow-up data and determine if the intervention was successful at reducing actual subsequent drinking behavior. Second, our sample consisted of primarily (78\%) women. Future research should examine whether the intervention affects men and women differently. Additional research evaluating multiple sessions and sampling multiple negative experiences would also be advantageous. We also understand that the inclusion criteria of one drinking occasion over the previous month is relatively liberal and that individuals who are not regular drinkers may still have participated in the study. However, we also believe that students who are normally not drinkers may still have heavy drinking experiences that are particularly positive and negative. We also believe that future research would benefit from examination of guilt- and shame-proneness (Tangney \& Dearing, 2002) as a moderator of intervention effects to evaluate whether there are certain individuals for whom this intervention may be particularly helpful.

In conclusion, behavior is - in part - shaped by recollection of past events and subsequent associations with current and desired future circumstances. This research presents an important step forward in the expressive writing approach to reducing alcohol use among college students. Results highlight the significance of activating repair-related emotions 
when asking students to re-experience past drinking events that were accompanied by unwanted consequences.

\section{Acknowledgments}

Preparation of this article was supported by National Institute on Alcohol Abuse and Alcoholism Grant F31AA020442.

\section{References}

Ames SC, Patten CA, Offord KP, Pennebaker JW, Croghan IT, Tri DM, et al. Expressive writing intervention for young adult cigarette smokers. Journal of Clinical Psychology. 2005; 61:15551570. [PubMed: 16193479]

Ames SC, Patten CA, Werch CE, Schroeder DR, Stevens SR, Fredrickson PA, et al. Expressive writing as a smoking cessation treatment adjunct for young adult smokers. Nicotine \& Tobacco Research. 2007; 9:185-194. [PubMed: 17365749]

Baddeley JL, Pennebaker JW. A postdeployment expressive writing intervention for military couples: a randomized controlled trial. Journal of Traumatic Stress. 2011; 24:581-585. [PubMed: 21887713]

Barclay LJ, Skarlicki DP. Healing the wounds of organizational injustice: examining the benefits of expressive writing. The Journal of Applied Psychology. 2009; 94:511-523. [PubMed: 19271805]

Borsari B, Murphy JG, Carey KB. Readiness to change in brief motivational interventions: a requisite condition for drinking reductions? Addictive Behaviors. 2009; 34:232-235. [PubMed: 18990500]

Collins SE, Logan DE, Neighbors C. Which came first: the readiness or the change? Longitudinal relationships between readiness to change and drinking among college drinkers. Addiction. 2010; 105:1899-1909. [PubMed: 20854333]

Collins R, Parks GA, Marlatt GA. Social determinants of alcohol consumption: the effects of social interaction and model status on the self-administration of alcohol. Journal of Consulting and Clinical Psychology. 1985; 53:189-200. [PubMed: 3998247]

Dearing RL, Stuewig J, Tangney JP. On the importance of distinguishing shame from guilt: relations to problematic alcohol and drug use. Addictive Behaviors. 2005; 30:1392-1404. [PubMed: 16022935]

DiClemente CC, Schlundt D, Gemmell L. Readiness and stages of change in addiction treatment. The American Journal on Addictions. 2004; 13:103-119. [PubMed: 15204662]

Dimeff, LA.; Baer, JS.; Kivlahan, DR.; Marlatt, GA. Brief Alcohol Screening and Intervention for College Students (BASICS): a harm reduction approach. New York, NY: Guilford Press; 1999.

Frattaroli J. Experimental disclosure and its moderators: a meta-analysis. Psychological Bulletin. 2006; 132:823-865. [PubMed: 17073523]

Greenberg MA, Wortman CB, Stone AA. Emotional expression and physical health: revising traumatic memories or fostering self-regulation? Journal of Personality and Social Psychology. 1996; 71:588-602. [PubMed: 8831163]

Harvey AG, Farrell C. The efficacy of a Pennebaker-like writing intervention for poor sleepers. Behavioral Sleep Medicine. 2003; 1:115-124. [PubMed: 15600133]

Heather, N.; Gold, R.; Rollnick, S. Readiness to change questionnaire: user's manual (technical report \#15). Kensington, Australia: National Drug and Alcohol Research Centre, University of New South Wales; 1991.

Hingson RW. Focus on: college drinking and related problems: magnitude and prevention of college drinking and related problems. Alcohol Research \& Health. 2010; 33:45-54. [PubMed: 23579935]

Hingson R, Heeren T, Winter M, Wechsler H. Magnitude of alcohol-related mortality and morbidity among U.S. college students ages 18-24: changes from 1998 to 2001. Annual Review of Public Health. 2005; 26:259-279.

Hingson RW, Zha W. Age of drinking onset, alcohol use disorders, frequent heavy drinking, and unintentionally injuring oneself and others after drinking. Pediatrics. 2009; 123:1477-1484. [PubMed: 19482757] 
Hoblitzelle, W. Differentiating and measuring shame and guilt: the relation between shame and depression. In: Lewis, H., editor. The role of shame in symptom formation. Hillsdale, NJ: Lawrence Erlbaum Associates, Inc.; 1987. p. 207-235.

Johnston, LD.; O’Malley, PM.; Bachman, JG.; Schulenberg, JE.; Miech, RA. Monitoring the future; national survey results on drug use, 1975-2013: Volume II, college students and adults ages 1955. Ann Arbor: Institute for Social Research, The University of Michigan; 2014.

Landau, LD.; Lifshitz, EM. Quantum mechanics: non-relativistic theory. 3rd. Vol. 3. Pergamon Press; 1977.

Lewis HB. Shame and guilt in neurosis. Psychoanalytic Review. 1971; 58:419-438. [PubMed: 5150685]

Lewis, H. The role of shame in depression over the life span. In: Lewis, H., editor. The role of shame in symptom formation. Hillsdale, NJ: Lawrence Erlbaum Associates, Inc.; 1987. p. 29-50.

Lu Q, Stanton AL. How benefits of expressive writing vary as a function of writing instructions, ethnicity and ambivalence over emotional expression. Psychology \& Health. 2010; 25:669-684. [PubMed: 20204944]

MacKinnon DP, Fritz MS, Williams J, Lockwood CM. Distribution of the product confidence limits for the indirect effect: program PRODCLIN. Behavior Research Methods. 2007; 39:384-389. [PubMed: 17958149]

MacKinnon DP, Lockwood CM, Hoffman JM, West SG, Sheets V. A comparison of methods to test mediation and other intervening variable effects. Psychological Methods. 2002; 7:83-104. [PubMed: 11928892]

Miller, WR.; Rollnick, S. Motivational interviewing: preparing people for change. 2nd. New York, NY: Guilford Press; 2002.

Miller WR, Rollnick S. Meeting in the middle: motivational interviewing and self-determination theory. The International Journal of Behavioral Nutrition and Physical Activity. 2012; 9:25. [PubMed: 22385872]

Norman SA, Lumley MA, Dooley JA, Diamond MP. For whom does it work? Moderators of the effects of written emotional disclosure in a randomized trial among women with chronic pelvic pain. Psychosomatic Medicine. 2004; 66:174-183. [PubMed: 15039501]

Pennebaker JW. Writing about emotional experiences as a therapeutic process. Psychological Science. 1997; 8:162-166.

Pennebaker JW, Colder M, Sharp LK. Accelerating the coping process. Journal of Personality and Social Psychology. 1990; 58:528-537. [PubMed: 2324942]

Pennebaker JW, Kiecolt-Glaser JK, Glaser R. Disclosure of traumas and immune function: health implications for psychotherapy. Journal of Consulting and Clinical Psychology. 1988; 56:239-245. [PubMed: 3372832]

Prochaska JO, DiClemente CC, Norcross JC. In search of how people change. Applications to addictive behaviors. The American Psychologist. 1992; 47:1102-1114. [PubMed: 1329589]

Rollnick S, Heather N, Gold R, Hall W. Development of a short 'readiness to change' questionnaire for use in brief, opportunistic interventions among excessive drinkers. British Journal of Addiction. 1992; 87:743-754. [PubMed: 1591525]

Schafer JL, Graham JW. Missing data: our view of the state of the art. Psychological Methods. 2002; 7:147-177. [PubMed: 12090408]

Smyth JM, Arigo D. Recent evidence supports emotion-regulation interventions for improving health in at-risk and clinical populations. Current Opinion in Psychiatry. 2009; 22:205-210. [PubMed: 19553877]

Smyth, JM.; Greenberg, MA. Scriptotherapy: the effects of writing about traumatic events. In: Duberstein, P.; Masling, JM., editors. Psychodynamic perspectives on sickness and health. Washington, DC: American Psychological Association; 2000. p. 121-160.

Smyth J, Helm R. Focused expressive writing as self-help for stress and trauma. Journal of Clinical Psychology. 2003; 59:227-235. [PubMed: 12552631]

Spera SP, Buhrfeind ED, Pennebaker JW. Expressive writing and coping with job loss. Academy of Management Journal. 1994; 37:722-733. 
Stanton, AL.; Danoff-Burg, S. Emotional expression, expressive writing, and cancer. In: Lepore, SJ.; Smyth, JM., editors. The writing cure: How expressive writing promotes health and emotional well-being. Washington, DC: American Psychological Association; 2002. p. 31-51.

Tangney JP. Moral affect: the good, the bad, and the ugly. Journal of Personality and Social Psychology. 1991; 61:598-607. [PubMed: 1960652]

Tangney, JP.; Dearing, RL. Shame and guilt. New York, NY: Guilford Press; 2002.

Tangney, JP.; Dearing, RL.; Wagner, PE.; Gramzow, R. The Test of Self-Conscious Affect-3 (TOSCA-3). Fairfax, VA: George Mason University; 2000.

Tangney JP, Stuewig J, Mashek DJ. Moral emotions and moral behavior. Annual Review of Psychology. 2007; 58:345-372.

White A, Hingson R. The burden of alcohol use: excessive alcohol consumption and related consequences among college students. Alcohol Research: Current Reviews. 2013; 35:201-218. [PubMed: 24881329]

Young CM, Rodriguez LM, Neighbors C. Expressive writing as a brief intervention for reducing drinking intentions. Addictive Behaviors. 2013; 38:2913-2917. [PubMed: 24064189]

\section{Appendix}

\section{Event-related Shame and Guilt}

\section{Directions}

Now try to place yourself back in the situation you just described as if you were reliving it in your mind. Imagine the feelings and thoughts you experienced back then. The items below describe some ways that you might have reacted to the situation. Think about each reaction and, on the scale below, please indicate the extent to which you experienced the thoughts and/or feelings described, using the scale provided.

\begin{tabular}{ll}
\hline Item & Guilt - Affect and Cognition Subscale \\
\hline 1 & You thought: "I should have been more prepared." \\
2 & You felt bad that you let people down. \\
3 & You felt uncomfortable. \\
4 & You felt regretful for not acting how you thought you should have acted. \\
5 & You felt bad. \\
6 & You felt guilty. \\
7 & You wondered if you could have done better. \\
8 & When you think about what happened, it weighs heavily on your mind. \\
9 & You felt sorry for how things played out. \\
10 & You felt like you disappointed people. \\
11 & Guilt - Reparative Behavior Subscale \\
12 & You decided to compensate for your shortcomings by trying harder in the future. \\
13 & You resolved to be better in the future. \\
14 & You resolved to become more committed to achieving your goals. \\
15 & You decided to make it up to people as soon as you could. \\
16 & You promised yourself that you would be better prepared in the future. \\
17 & You were willing to accept the consequences of your actions and felt like you deserved them.
\end{tabular}




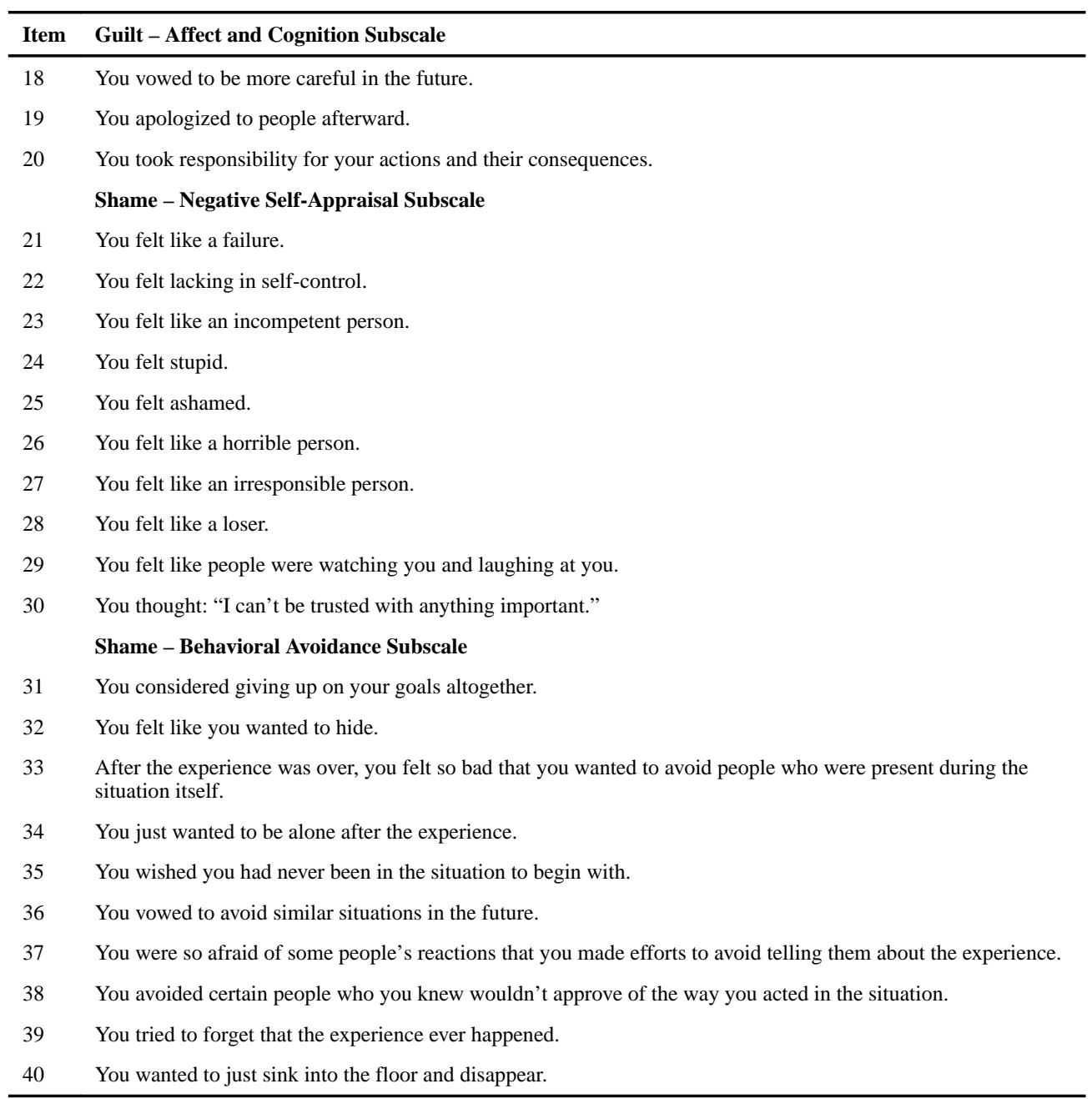




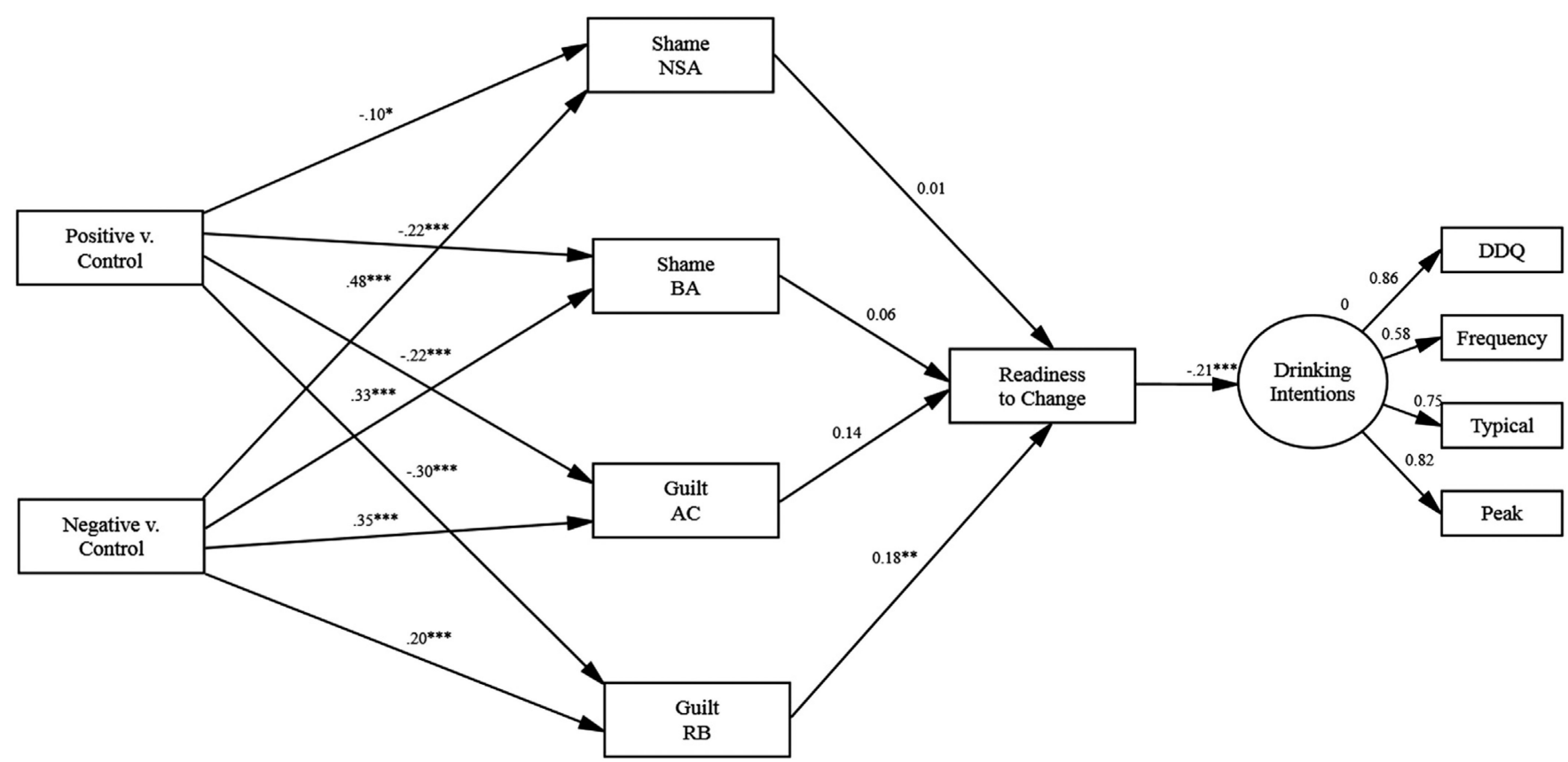

Fig. 1.

Mediational model including standardized coefficients for intervention effects, event-related shame and guilt, readiness to change, and drinking intentions. Note: Typical drinking (i.e., drinks per week) was included as a covariate for readiness to change $(\beta=.20, p<.001)$ and drinking intentions $(\beta=.80, p<.001)$, but was not included in the figure for clarity. $* p<$. $05 ; * * p<.01 ; * * * p<.001$. 


\section{Table 1}

Descriptive statistics by condition.

\begin{tabular}{lrrr}
\hline Variable & Condition & & \\
\cline { 2 - 4 } & $\begin{array}{r}\text { Positive } \\
(\boldsymbol{n}=\mathbf{~ 1 4 6}) \\
\mathbf{M}(\mathbf{S D})\end{array}$ & $\begin{array}{r}\text { Negative } \\
(\boldsymbol{n}=\mathbf{1 3 8}) \\
\mathbf{M}(\mathbf{S D})\end{array}$ & $\begin{array}{r}\text { Control } \\
(\boldsymbol{n}=\mathbf{1 4 5}) \\
\mathbf{M}(\mathbf{S D})\end{array}$ \\
\hline Shame (Negative self-appraisal) & $1.95(1.33)$ & $4.16(1.81)$ & $2.32(1.49)$ \\
Shame (Behavioral avoidance) & $1.71(1.16)$ & $3.57(1.61)$ & $2.46(1.50)$ \\
Guilt (Affect and cognition) & $2.00(1.38)$ & $4.22(1.85)$ & $2.87(1.61)$ \\
Guilt (Reparative behavior) & $2.90(1.80)$ & $4.90(1.67)$ & $4.12(1.66)$ \\
Readiness to change & $.11(1.29)$ & $.58(1.37)$ & $.29(1.25)$ \\
Intended drinks per week & $6.74(5.33)$ & $5.40(5.35)$ & $6.79(7.14)$ \\
Intended drinking frequency & $5.59(2.09)$ & $4.79(2.13)$ & $5.15(2.29)$ \\
Intended typical drinks & $4.06(2.15)$ & $3.80(1.96)$ & $4.27(2.53)$ \\
Intended peak drinks & $2.38(1.79)$ & $2.20(1.80)$ & $2.56(1.88)$ \\
\hline
\end{tabular}




\section{롤 \\ 亩}

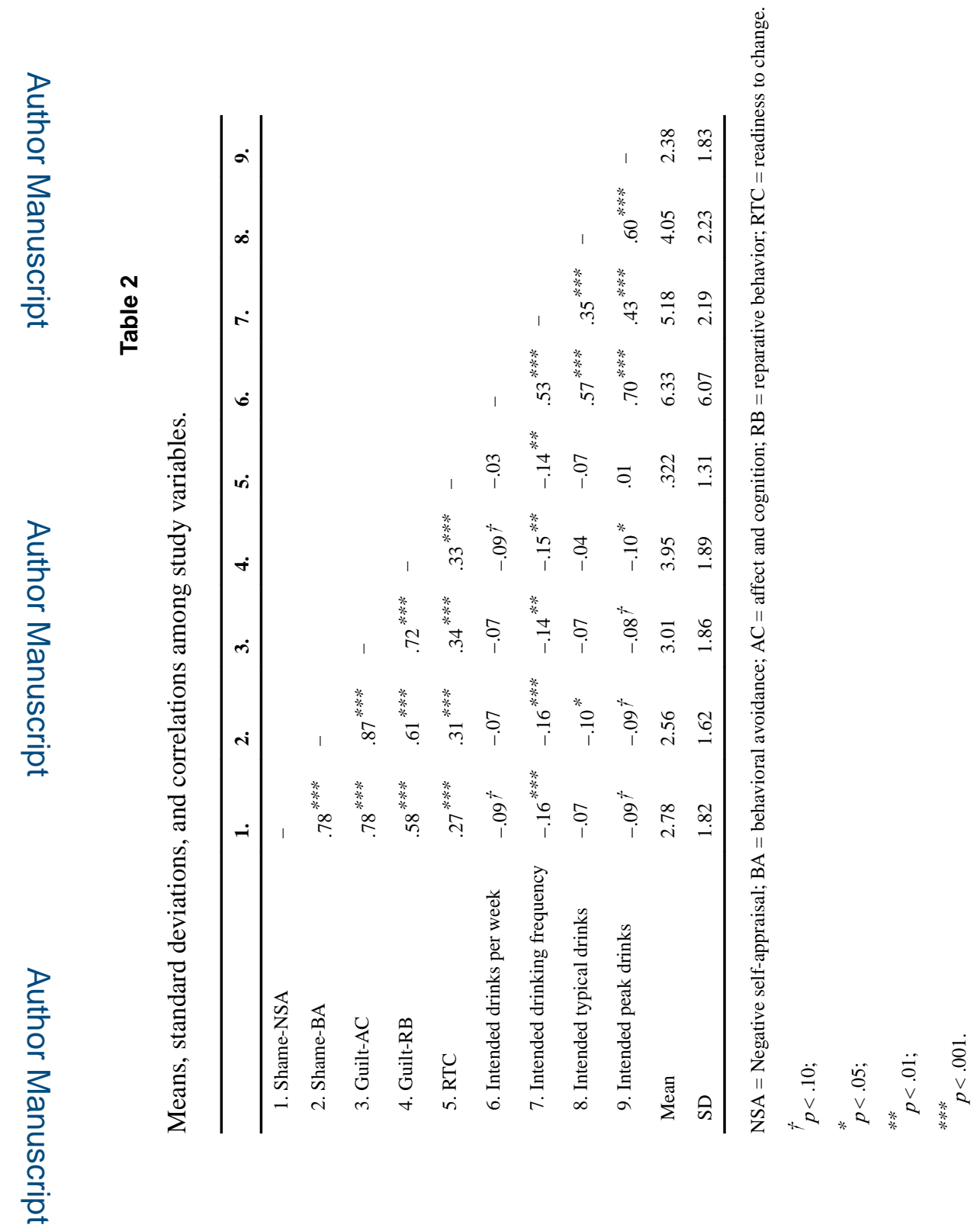

Alcohol. Author manuscript; available in PMC 2016 June 24. 


\section{롤 \\ 일}

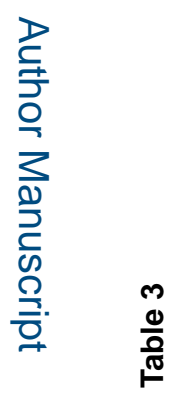

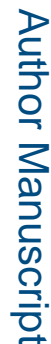

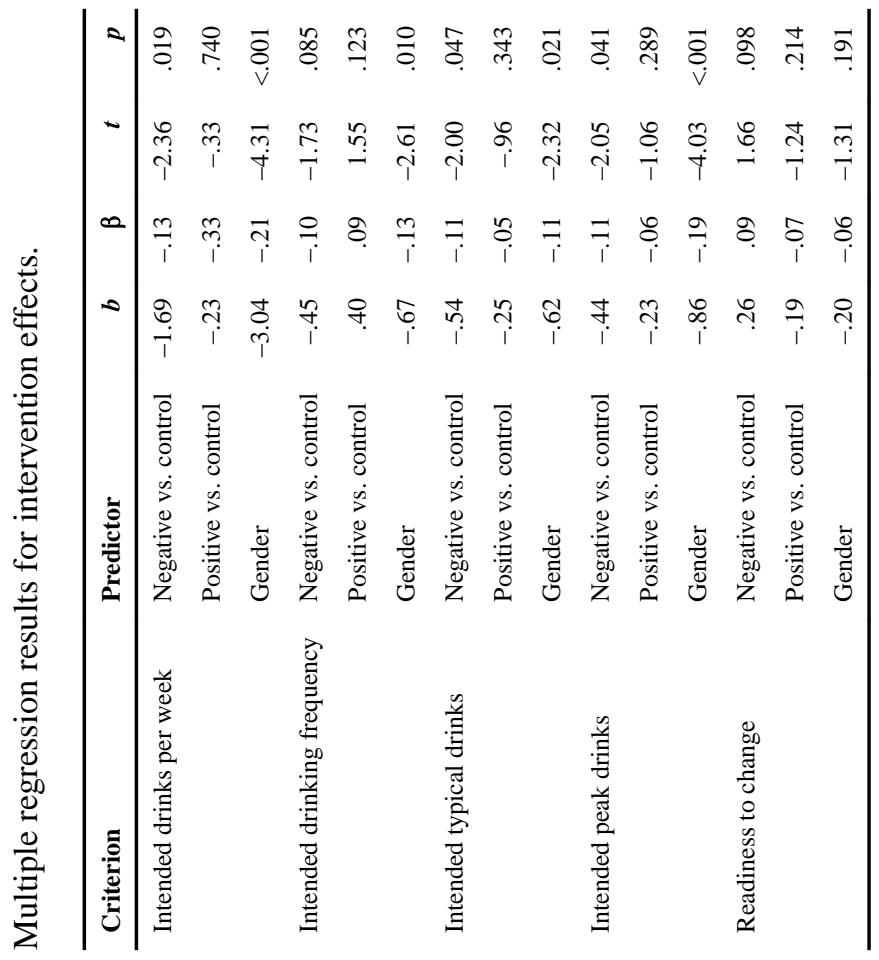

Alcohol. Author manuscript; available in PMC 2016 June 24. 